\title{
Palmar Dermatoglyphics of Down's Syndrome: Revisited
}

\author{
Chris G. Plato ${ }^{[21]}$, James J. Cereghino, and Florence S. Steinberg \\ National Institute of Child Health and Human Development and National Institute of Neurological Diseases and Stroke, National Institutes \\ of Health, Bethesda, Maryland, USA
}

\begin{abstract}
Extract
In previous reports the subclassifications for the terminations of the $\mathrm{C}$ line of the palm and for the interdigital palmar areas have been described. These subclassifications, as well as those of Cummins and Midlo for the hypothenar and thenar/I areas, were applied to anthropologic data and showed strong bilateral and racial polymorphism. The present study is an effort to determine the usefulness of these methods in investigations of clinical data. A well defined anomaly, Down's syndrome, which has known dermatoglyphic peculiarities, was chosen for this test. The study involved 145 male and 120 female patients and 108 male and 114 female control subjects. All subjects were unrelated Caucasians. Significant differences between the patient and control subjects were encountered in the subclassifications of the $\mathrm{C}$ line terminations and in the hypothenar area patterns. Significant differences were observed in the frequency of patterns in the thenar/I area as well as the expected differences in the simial lines. Sydney line frequencies showed no significant differences.
\end{abstract}

\section{Speculation}

The results of the present study suggest that the subclassifications of the palmar patterns and the $G$ line terminations are of value in the investigation of clinical data by offering further diagnostic criteria not revealed by gross dermatoglyphic evaluation.

\section{Introduction}

Characteristic dermatoglyphic patterns of the palms, digits, and soles are well described in Down's syndrome $[3,5,6,8,15,16,18,19]$. Characteristic patterns of dermatoglyphics in other medical conditions are being reported with increasing frequency $[1,2,7,9,14$, 17, 20].

The digital and palmar dermatoglyphic features of Down's syndrome are: excess of ulnar loops, occasional radial loops on the 4 th and 5 th digits, distally located axial triradii, wide atd angles, and excess of patterns in the hypothenar and III interdigital areas. Dermatoglyphics of the sole in Down's syndrome are character- ized by an arch tibial in the hallucal area. In addition to the dermatoglyphic features, there is high incidence of the simian line in the palm.

Penrose and Loesch [10] introduced and demonstrated the usefulness of a method for classifying palmar patterns on the basis of topologic considerations. Plato [11] presented a method for classifying the $\mathrm{C}$ line terminations. Line $\mathrm{C}$ is the only main line of the palm which is truly polymorphic, and which demonstrates qualitative (directional) as well as quantitative variation manifested in the degree of transversality and size reduction culminating in complete suppression. The $\mathrm{A}$ and the $\mathrm{B}$ palmar lines almost always follow an ulnar direction, and the $\mathrm{D}$ line has a radial pathway charac- 

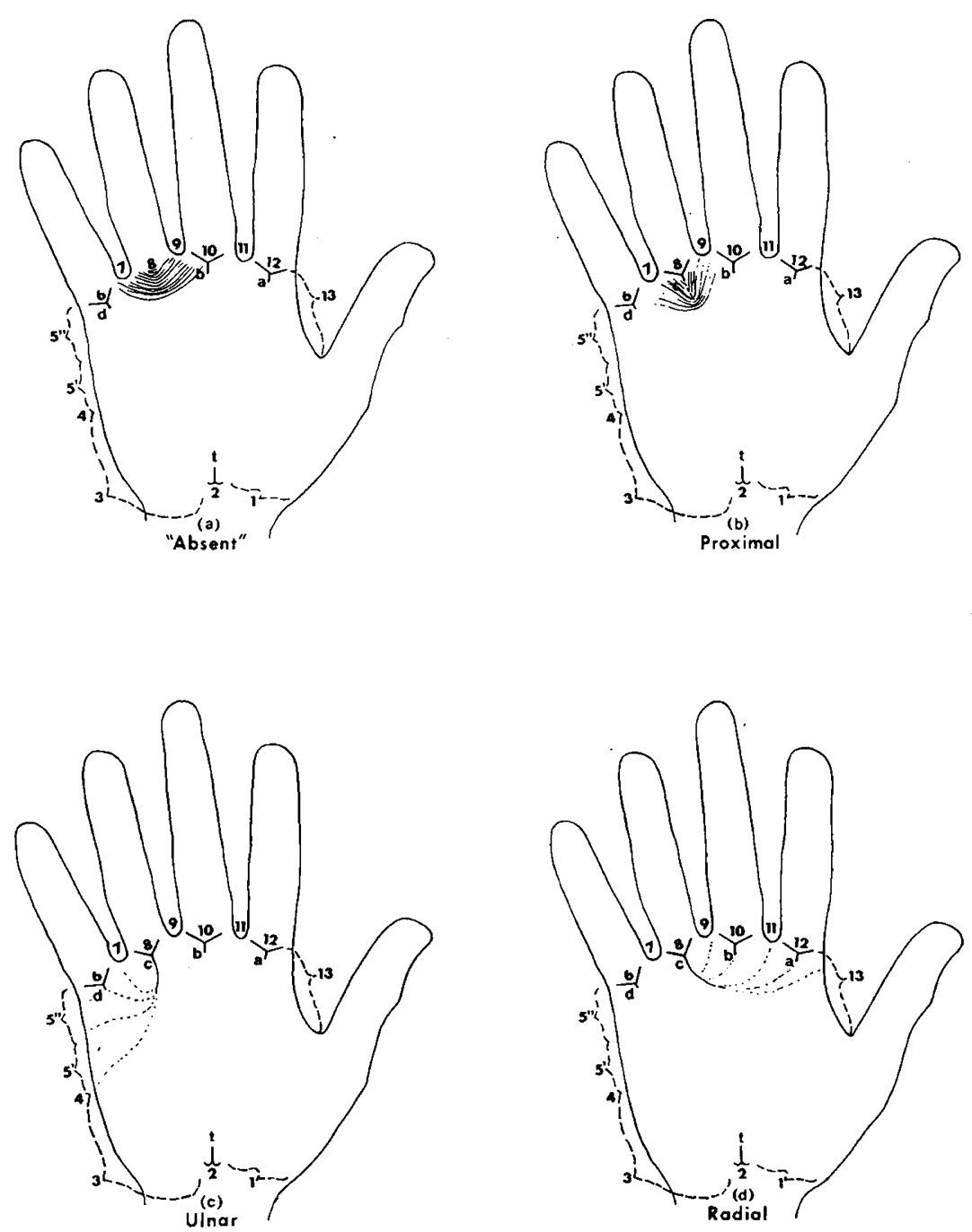

Fig. 1. C line palmar classification [1 1]. (Reproduced with permission, American Journal of Physical Anthropology.)

teristically. Line $\mathrm{C}$ may have an ulnar, radial, or proximal direction, or may be absent when there is no $\mathrm{c}$ triradius. In view of this variability, Plato [11] proposed that the $\mathrm{G}$ line terminations be classified into four modal types depending on the direction of the pathway (Fig. 1). The classifications are: (1) absent, when the $c$ triradius is not present; (2) proximal, with terminations at position $8(\mathrm{X}, \mathrm{x})$; (3) ulnar, with terminations at positions $4,5,6$, or 7 ; and (4) radial, with terminations at positions $9,10,11,12$, or 13 .

Plato et al. [12] developed a measurement of the direction of the $\mathrm{C}$ line called the radial/ulnar $(\mathrm{R} / \mathrm{U}$ ratio). Plato and Wertelecki [13] subclassified palmar interdigital patterns into 10 different patterns (Fig. 2) based on the direction of the main line that forms the pattern and the presence of an accessory triradius. Detailed discussion and illustrative examples were given in earlier reports $[12,13]$. These subclassifications of the interdigital patterns, the modal types of the $\mathrm{C}$ line, and the resulting $R / U$ ratio have been of value in population and anthropologic studies [12, 13], demonstrating a strong bilateral difference as well as racial and population differences.

To determine whether the modal types of the $\mathrm{C}$ line, the $\mathrm{R} / \mathrm{U}$ ratio, and the subtypes of the interdigital pattern are of value in the study of clinical as well as anthropologic dermatoglyphic data, we applied these classifications to patients with Down's syndrome.

\section{Material and Methods}

The study population was composed of 145 male and 120 female patients with Down's syndrome (age range from birth to 58 years) and 108 male and 114 female 
controls (age 7 years). An additional 203 male and 204 female controls were studied for the simian and Sydney line comparisons. Both patients and controls were unrelated Caucasians. The palmar and digital prints of the Down's syndrome patients were collected under the supervision of Dr. Fred Rosner at three Virginia State Hospitals and Dr. Felix de la Cruz at the Children's Diagnostic and Study Branch of the National Institute of Child Health and Human Development. The prints from Dr. Rosner have been described in a prior publication [14]; diagnoses of these patients were based on clinical examination. The Children's Diagnostic and Study Branch patients had trisomy 21 karyotypes. The palmar and digital prints of the controls were collected during their 7 th year examination in the NINDS perinatal collaborative study at the Boston Children's Hospital under the supervision of Dr. James Drobaugh. The controls had no observed abnormalities upon periodic physical and neurologic examinations, no birth defects, and their I.Q.'s were above 70 on repeated psychometric examinations.

Prints from the patients were made by the standard ink method, and those of the controls were made by the Faurot inkless method.

All prints were evaluated for the modal types of the $\mathrm{C}$ line; the $\mathrm{R} / \mathrm{U}$ ratio; the subtypes of the interdigital patterns; the subtypes of the thenar/I and hypothenar areas as described by Cummins and Midlo [4]; the simian line, with distinction between complete and aberrant types; and the Sydney line, with distinction between complete and aberrant types. All prints were also evaluated for bilateral symmetry.

The complete simian line is the classic single transverse crease produced by the fusion of the proximal and distal creases and the aberrant simian line is composed of all variations. The complete Sydney line is represented by the uninterrupted extension of the proximal crease to the ulnar margin of the palm. The aberrant Sydney line does not necessarily reach the ulnar margin, although it does extend well beyond the d triradius.

Patients were initially divided into three age groups: (I) birth to 10 years, (2) 10-20 years, and (3) over 20 years. Since no statistical differences were observed between age groups, the age groups were pooled.

\section{Results and Discussion}

The results are summarized in Tables I-VII. Only individuals with complete sets of data were included. Evaluation of each dermatoglyphic feature is described below.
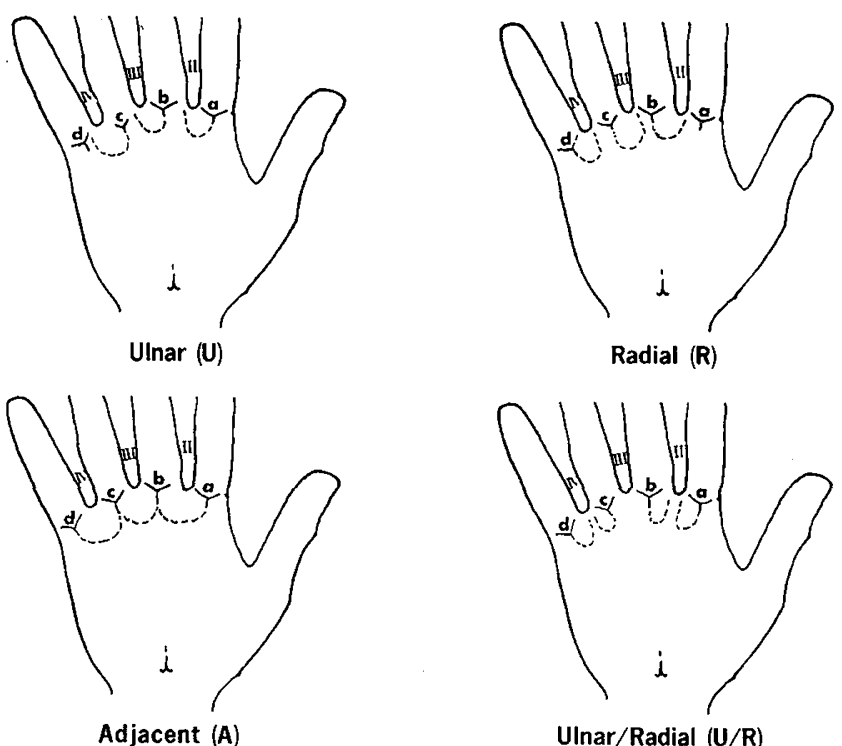

Ulnar/Radial (U/R)
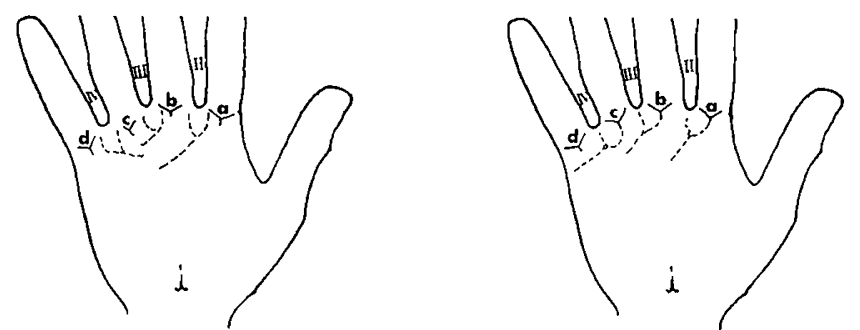

Accessory $(Y)$ (triradius)

UInar/Accessory $(U / Y)$

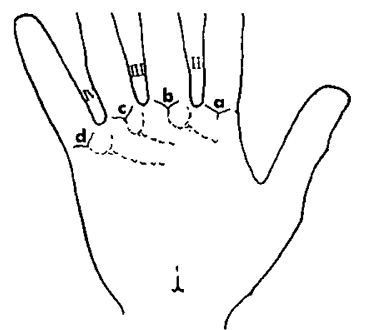

Radial/Accessory $(\mathbf{R} / \mathrm{Y})$

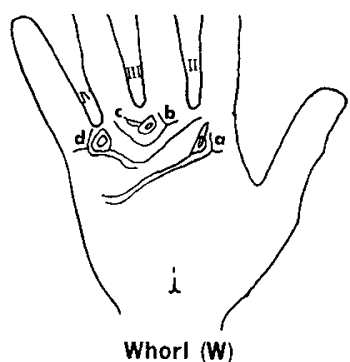

Fig. 2. Plato and Wertelecki subclassification of interdigital palmar Patterns [13]. Illustrated are the seven loop subclassifications and the whorl pattern. Open fields and vestiges are not illustrated. (Reproduced with permission, American Journal of Physical Anthropology.)

\section{Modal Types of the $C$ Line and $R / U$ Ratio}

In most of the racial groups studied previously [11], a higher incidence of radial type $\mathrm{C}$ lines in right hands has been demonstrated, whereas as excess of ulnar types has been found in left hands; the maximum $\mathrm{R} / \mathrm{U}$ ratio for left hands is below the lower limit of the $R / U$ ratio for right hands. The range of $R / U$ ratios is given in Table $\mathrm{I}$. Also included are values for the controls which are close to those of the Caucasian 
Table $I$. Range of the $\mathrm{R} / \mathrm{U}$ ratios of the modal type of $\mathrm{C}$ line in six population groups (derived from Plato [11]) and in study population 1

\begin{tabular}{lccc}
\hline & $\mathrm{L}$ & $\mathrm{R}$ & $\mathrm{C}+\mathrm{R}$ \\
\hline Oriental & $0.06-0.23$ & $0.24-0.86$ & $0.15-0.48$ \\
Oceanian & $0.04-0.31$ & $0.25-0.65^{1}$ & $0.15-0.81$ \\
Negro & $0.18-0.44$ & $0.72-0.73$ & $0.40-0.58$ \\
American Indian & $0.14-0.37$ & $0.63-1.00$ & $0.42-0.62$ \\
Caucasian & $0.33-0.92$ & $0.90-2.62$ & $0.73-1.51$ \\
Caucasian control & $0.51-0.54$ & $0.90-2.14$ & $0.71-1.34$ \\
$\quad$ subjects in present & & & \\
$\quad$ study & & & \\
Asian Indian & $0.84-1.43$ & $1.75-2.50$ & $1.30-1.60$ \\
Down's patients in & $5.79-5.84$ & $10.41-10.81$ & $8.10-8.32$ \\
$\quad$ present study & & & \\
\hline
\end{tabular}

${ }^{1}$ Excluding the Anga of New Guinea who have a ratio of 1.70 .

group and values for the patients which are considerably different.

Differences in the frequency of the radial and ulnar types (Table II) are mainly responsible for the significant difference $(P<0.001)$ in the modal types of the $\mathrm{C}$ line between patients and controls for both sexes.

In patients the proportion of proximal modal type $\mathrm{C}$ line is most frequently observed in the left hand and less frequently observed in the right hand. Among controls, the $\mathrm{C}$ line is equally distributed on both hands. The Down's patients, furthermore, demonstrated in both hands a marked increase over the controls in the frequency of the radial types, with a corresponding decrease of ulnar types. The $\mathrm{R} / \mathrm{U}$ ratio for the Down's patients was 5-12 times higher than that expected for a Caucasian population, which has a ratio higher than those for other ethnic groups (Table I). Because a higher $\mathrm{R} / \mathrm{U}$ ratio indicates a marked degree of transverseness in the direction of the palmar ridges, such a finding would be expected in Down's patients since transverseness is characteristic of their palmar dermatoglyphics. In our series, the same modal type of $\mathrm{C}$ line was present in both hands in $61.5 \%$ of the male patients and in $47.7 \%$ of the male controls, which indicates a higher degree of bilateral symmetry among male patients. In females the degree of bilateral symmetry was $67 \%$ for the patients and $66 \%$ for the controls. Cummins [3] has reported a similar reduction in bilateral asymmetry of the main line index in Down's patients.

\section{Hypothenar Area Patterns}

Cummins [3] and subsequent investigators have described an excess of patterns, particularly of the ulnar type, in the hypothenar area in Down's patients. Our results (Table III) agree with these findings. We also observed higher frequencies of single loops and of whorls in the Down's patients. In the single loop subtypes, almost all of the loops in either hand of the patients were of the ulnar type. Of the 216 patients, there was only one female with radial hypothenar loops. This is significant since our control subjects,

Table II. The modal types of the $\mathrm{C}$ line and the $\mathrm{R} / \mathrm{U}$ ratio in patients with Down's syndrome and in control subjects ${ }^{1}$

\begin{tabular}{|c|c|c|c|c|c|c|c|c|c|c|c|c|}
\hline \multirow{2}{*}{ Subjects } & \multirow{2}{*}{ Sex } & \multirow{2}{*}{$N$} & \multicolumn{2}{|c|}{ Absent } & \multicolumn{2}{|c|}{ Proximal } & \multicolumn{2}{|c|}{ Ulnar } & \multicolumn{2}{|c|}{ Radial } & \multicolumn{2}{|c|}{$\mathrm{R} / \mathrm{U}$ ratio } \\
\hline & & & $\mathrm{L}$ & $\mathrm{R}$ & I & $\mathbf{R}$ & $\mathrm{L}$ & $\mathrm{R}$ & $\mathrm{L}$ & $\mathrm{R}$ & $\mathrm{I}$ & $\mathbf{R}$ \\
\hline Down's & $\mathbf{M}$ & 135 & 5.2 & 5.2 & 29.6 & 10.4 & 9.6 & 7.4 & 55.6 & 77.0 & 5.79 & 10.41 \\
\hline Control & $\mathbf{M}$ & 107 & 5.6 & 3.7 & 19.6 & 15.9 & 49.5 & 25.2 & 25.2 & 55.1 & 0.51 & 2.19 \\
\hline Down's & $\mathrm{F}$ & 106 & 7.5 & 4.7 & 15.1 & 6.6 & 11.3 & 7.5 & 66.0 & 81.1 & 5.84 & 10.81 \\
\hline Control & $\mathrm{F}$ & 109 & 8.3 & 5.5 & 11.0 & 11.0 & 52.3 & 44.0 & 28.4 & 39.4 & 0.54 & 0.90 \\
\hline
\end{tabular}

Values are expressed as percentages.

Table III. Hypothenar area patterns in patients with Down's syndrome and in control subjects ${ }^{1}$

\begin{tabular}{|c|c|c|c|c|c|c|c|c|c|c|c|c|c|c|c|c|c|c|c|c|c|c|}
\hline \multirow{3}{*}{ Subjects } & \multirow{3}{*}{ Sex } & \multirow{3}{*}{$N$} & \multicolumn{10}{|c|}{ Patterns } & \multicolumn{10}{|c|}{ Single loop pattern } \\
\hline & & & \multicolumn{2}{|c|}{ Open/arch } & \multicolumn{2}{|c|}{ Vestige } & \multicolumn{2}{|c|}{ Single loop } & \multicolumn{2}{|c|}{ Double loop } & \multicolumn{2}{|c|}{ Whorl } & \multicolumn{2}{|c|}{ Number ${ }^{2}$} & \multicolumn{2}{|c|}{ Ulnar } & \multicolumn{2}{|c|}{ Radial } & \multicolumn{2}{|c|}{ Distal } & \multicolumn{2}{|c|}{ Proximal } \\
\hline & & & $\mathrm{x}$ & $\mathbf{R}$ & $\mathrm{L}$ & $\mathbf{R}$ & $\mathbf{L}$ & $\mathbf{R}$ & $\mathrm{L}$ & $\mathbf{R}$ & $\mathbf{L}$ & $\mathrm{R}$ & L & $\mathbf{R}$ & L & $\mathbf{R}$ & $\mathbf{L}$ & $\mathrm{R}$ & $\mathbf{L}$ & $\mathbf{R}$ & $\mathrm{L}$ & $\mathbf{R}$ \\
\hline Down's & $M$ & 115 & 44.3 & 39.1 & 2.6 & 1.7 & 49.6 & 49.6 & & & 3.5 & 9.6 & 57 & 57 & 100.0 & 98.2 & & & & 1.8 & & \\
\hline Control & $\mathbf{M}$ & 106 & 76.4 & 69.8 & 1.9 & 1.9 & 17.0 & 19.8 & 1.9 & 3.8 & 2.8 & 4.7 & 18 & 21 & 16.7 & 4.8 & 72.2 & 85.7 & 11.1 & 4.8 & & 4.8 \\
\hline Down's & $\mathrm{F}$ & 101 & 44.6 & 38.6 & 1.0 & 2.0 & 49.5 & 52.5 & 1.0 & & 4.0 & 16.8 & 50 & 43 & 98.0 & 97.7 & 2.0 & 2.3 & & & & \\
\hline Control & $\mathbf{F}$ & 110 & 71.8 & 69.3 & 1.8 & 2.7 & 22.7 & 28.2 & 2.7 & 3.6 & 0.9 & 1.8 & 25 & 31 & 28.0 & 22.6 & 36.0 & 54.8 & 36.0 & 16.1 & & 6.5 \\
\hline
\end{tabular}

Values are expressed as percentages.

2 Number observed. 
and Caucasians in general, have high frequencies of hypothenar radial loops [13].

\section{Thenar/I Area Patterns}

There was a paucity of thenar/I patterns among the Down's patients (Table IV). The rarity of loops, either single, or in combination with other loops or vestiges, was pronounced. There were only 3 loops, all single,

Table IV. Thenar/I area patterns in patients with Down's syndrome and control subjects ${ }^{1}$

\begin{tabular}{|c|c|c|c|c|}
\hline & \multicolumn{2}{|c|}{ Male } & \multicolumn{2}{|c|}{ Female } \\
\hline & Down's & Controls & Down's & Controls \\
\hline$N$ & 135 & 106 & 96 & 110 \\
\hline \multicolumn{5}{|c|}{ Open/arch } \\
\hline $\mathrm{L}$ & 97.8 & 83.0 & 99.0 & 90.0 \\
\hline $\mathrm{R}$ & 99.3 & 95.3 & 97.9 & 93.6 \\
\hline \multicolumn{5}{|c|}{ Vestige } \\
\hline $\mathrm{L}$ & 0.7 & 2.8 & 1.0 & \\
\hline $\mathrm{R}$ & 0.7 & & 1.0 & 2.7 \\
\hline \multicolumn{5}{|c|}{ Total Loops } \\
\hline $\mathrm{L}$ & 1.5 & 13.2 & & 9.0 \\
\hline $\mathrm{R}$ & & 3.7 & 1.0 & 3.6 \\
\hline \multicolumn{5}{|c|}{ Loop } \\
\hline$L^{n}$ & 1.5 & 6.6 & & 2.7 \\
\hline $\mathrm{R}$ & & 0.9 & 1.0 & 2.7 \\
\hline \multicolumn{5}{|c|}{ Loop/vestige } \\
\hline $\mathrm{L}^{-}$ & & 4.7 & & 1.8 \\
\hline $\mathrm{R}$ & & 2.8 & & 0.9 \\
\hline \multicolumn{5}{|c|}{ Loop/loop } \\
\hline$L^{2}$ & & 1.9 & & 4.5 \\
\hline $\mathrm{R}$ & & & & \\
\hline \multicolumn{5}{|c|}{ Whorl } \\
\hline L & & 0.9 & & 0.9 \\
\hline $\mathrm{R}$ & & & & \\
\hline
\end{tabular}

${ }^{\mathrm{I}}$ Values are expressed as percentages. in the palms of the patients compared with 33 in palms of the controls. The frequencies of the types of thenar/I patterns among the controls agree closely with those of an earlier report [13].

\section{Interdigital Patterns}

The interdigital subtypes are illustrated in Figure 2. Ulnar loops are formed by the ulnar path of a main line and radial loops are formed by the radial path of a main line. Adjacent (A) loops result from the joining of two adjacent main lines with opposite directions. UInar/radial $(\mathbf{U} / \mathbf{R})$ subtypes have two loops in the same area, one formed by the ulnar direction of one line and the other by the radial path of its adjacent. Accessory triradius ( $\mathrm{Y}$ ) loops are formed exclusively by the presence of an accessory triradius. Ulnar/accessory $(\mathrm{U} / \mathrm{Y})$ and $\mathrm{radial} / \mathrm{accessory}(\mathrm{R} / \mathrm{Y})$ denote the presence of loops formed by the combination of an ulnar or a radial path of a main line, respectively, and an accessory triradius [13].

\section{Interdigital Area Patterns}

The excess of patterns in this area is one of the cardinal criteria of Down's syndrome. In our findings (Table V), there was, as expected, a significant excess of loops among the Down's patients $(P<0.001)$. There was, however, no significant difference in the frequency of the loop subtypes, since, in both the patient and control samples, the loops in this area were mainly of the radial type resulting from the radial direction of the $\mathrm{C}$ line. There seemed to be a decrease of $\mathrm{Y}$ type loops among the patients but the numbers were too small for comparison.

Table V. Patterns in the II, III, and IV interdigital areas of the palms of patients with Down's syndrome and of control subjects ${ }^{1}$

\begin{tabular}{|c|c|c|c|c|c|c|c|c|c|c|c|c|c|c|c|c|c|c|c|c|c|c|c|c|c|c|c|}
\hline \multirow{3}{*}{$\begin{array}{l}\text { Inter- } \\
\text { digital } \\
\text { area }\end{array}$} & \multirow{3}{*}{ Subjects } & \multirow{3}{*}{ Sex } & \multirow{3}{*}{$N$} & \multirow{2}{*}{\multicolumn{2}{|c|}{ Open/arch }} & \multirow{2}{*}{\multicolumn{2}{|c|}{ Vestige }} & \multirow{2}{*}{\multicolumn{2}{|c|}{ Loop }} & \multirow{2}{*}{\multicolumn{2}{|c|}{ Whorl }} & \multicolumn{16}{|c|}{ Loops } \\
\hline & & & & & & & & & & & & \multicolumn{2}{|c|}{ Number ${ }^{2}$} & \multicolumn{2}{|c|}{ U } & \multicolumn{2}{|c|}{$\mathrm{R}$} & \multicolumn{2}{|c|}{ A } & \multicolumn{2}{|c|}{$\mathrm{U} / \mathrm{R}$} & \multicolumn{2}{|c|}{$\mathrm{Y}$} & \multicolumn{2}{|c|}{$\mathrm{U} / \mathrm{Y}$} & \multicolumn{2}{|c|}{$\mathrm{R} / \mathrm{Y}$} \\
\hline & & & & $\mathbf{L}$ & $\mathrm{R}$ & $\mathrm{L}$ & $\mathrm{R}$ & L & $\mathrm{R}$ & $\mathrm{L}$ & $\mathrm{R}$ & $\mathrm{L}$ & $\mathrm{R}$ & L & $\mathrm{R}$ & L & $\mathrm{R}$ & L & R & L & $\mathrm{R}$ & $\mathrm{L}$ & $\mathrm{R}$ & $\mathrm{L}$ & $\mathrm{R}$ & L & $\mathrm{R}$ \\
\hline \multirow[t]{4}{*}{ III } & Down's & M & 133 & 15.0 & 11.3 & 29.3 & 11.3 & 55.6 & 77.4 & & & 74 & 103 & 1.4 & 2.9 & 97.3 & 90.3 & 1.4 & 6.8 & & & & & & & & \\
\hline & Control & M & 106 & 44.3 & 29.3 & 30.2 & 19.8 & 25.5 & 50.9 & & & 27 & 54 & & 1.9 & 100.0 & 90.7 & & 7.4 & & & & & & & & \\
\hline & Down's & $F$ & 106 & 18.7 & 12.3 & 15.1 & 14.2 & 66.0 & 81.1 & & & 70 & 86 & & & 986 & 95.3 & 1.4 & 3.5 & & & & 1.2 & & & & \\
\hline & Control & $\mathrm{F}$ & 108 & 58.3 & 43.5 & 15.7 & 14.8 & 25.9 & 41.7 & & & 28 & 45 & & 2.2 & 96.4 & 86.7 & & 6.7 & & & 3.6 & 4.4 & & & & \\
\hline \multirow[t]{4}{*}{ IV } & Down's & M & 134 & 57.5 & 79.1 & 29.1 & 11.2 & 13.4 & 9.7 & & & 18 & 13 & 55.6 & 30.8 & 5.6 & 30.8 & & & 11.1 & & 11.1 & 23.1 & & & 16.7 & 15.4 \\
\hline & Control & M & 107 & 19.6 & 43.0 & 27.1 & 19.6 & 50.5 & 35.5 & 2.8 & 1.9 & 54 & 38 & 51.9 & 31.6 & 35.2 & 34.2 & 3.7 & 10.5 & 5.6 & 2.6 & & 10.5 & & & 3.7 & 10.5 \\
\hline & Down's & $\mathbf{F}$ & 105 & 61.0 & 80.0 & 19.0 & 9.5 & 20.0 & 10.5 & & & 21 & 11 & 42.9 & 45.5 & 14.3 & 36.4 & & & & & 28.6 & 18.2 & & & 14.3 & \\
\hline & Control & F & 110 & 20.9 & 31.8 & 13.6 & 14.5 & 65.5 & 53.6 & & & 72 & 59 & 43.1 & 49.2 & 33.3 & 20.3 & 6.9 & 11.9 & 5.6 & & 4.2 & 6.8 & & & 6.9 & 11.9 \\
\hline \multirow[t]{4}{*}{ II } & Down's & $\mathbf{M}$ & 135 & 97.0 & 96.3 & & & 3.0 & 3.7 & & & 4 & 5 & $1^{2}$ & 12 & & & & & & & $2^{2}$ & & $1^{2}$ & $4^{2}$ & & \\
\hline & Control & M & 106 & 97.2 & 91.5 & & 3.8 & 2.8 & 4.7 & & & 3 & 5 & & $1^{2}$ & & & & & & & $2^{2}$ & & $1^{2}$ & $4^{2}$ & & \\
\hline & Down's & $\mathbf{F}$ & 96 & 95.8 & 97.9 & 1.0 & & 3.1 & 2.1 & & & 3 & 2 & $1^{2}$ & & & & & & & & & 12 & $2^{2}$ & $1^{2}$ & & \\
\hline & Control & F & 110 & 96.4 & 90.0 & 1.8 & 2.7 & 1.8 & 7.3 & & & 2 & 8 & & & & & & & & & $1^{2}$ & & $1^{2}$ & $8^{2}$ & & \\
\hline
\end{tabular}

1 Values are expressed as percentages.

2 Number observed. 


\section{Interdigital Area Patterns}

There was a significant decrease of loop patterns in the Down's patients as compared with the controls (Table V). This, again, was to be expected since most of the $\mathrm{C}$ line terminations in Down's patients are of the radial type, thus leaving the IV interdigital area relatively free of loop patterns. In the loop subtypes, both the patients and controls had a similar frequency of ulnar types, although the frequency of ulnar loops was higher in the left palms of the males of both groups. The left palms of male and female patients had fewer radial loops than did those of the controls. Of the remaining subtypes, the Down's patients showed an excess of loops due to an accessory triradius $(\mathrm{Y})$ or in connection with a radial path of the $\mathrm{D}$ line $(\mathrm{R} / \mathrm{Y})$. There were no adjacent types among the patients. Since the total number of loops in the IV interdigital area of the patients' palms was small, it was not possible to carry out statistical tests for the minor subtypes. The above trends seem interesting and worth pursuing further with a larger sample.

\section{Interdigital Area Patterns}

There were no obvious differences in patterns between patients and controls in this area (Table V).

\section{Palmar Creases}

The patients of both sexes demonstrated an excess of both simian and Sydney lines (Table VI) of both the complete and the aberrant types. Of the two palmar lines, the simian is more useful in identification of Down's patients. In our patients, $57.9 \%$ of the males and $53.3 \%$ of the females had either an aberrant or complete simian line; in the controls these frequencies were $11.3 \%$ and $5.9 \%$, respectively. When the two palmar creases were considered together, $80.7 \%$ of the male and $82.5 \%$ of the female patients had either a complete or aberrant simian or Sydney line. In the control sample, these frequencies were $28.1 \%$ for the males and $26.0 \%$ for the females. When aberrant types of either crease were considered as negative and excluded, $62.1 \%$ of the male and $64 \%$ of the female patients had a complete simian or Sydney line; the respective frequencies for the controls were $16.3 \%$ and $13.2 \%$. It is thus apparent that the simian line alone constitutes a better criterion for Down's syndrome than does the Sydney line.

\section{Bilateral Symmetry}

The five palmar configuration areas were evaluated for bilateral symmetry (Table VII). In all areas the Down's patients, with one exception, had a higher frequency of total bilateral symmetry than did the controls, although these differences were not significant. Considerable differences between patients and controls became apparent when the types of asymmetry were considered.

In the hypothenar and III interdigital areas, the symmetry in the palms of the controls was due to bilateral absence of patterns, whereas most of the symmetry of the Down's patients was due to the presence of the same pattern in both hands. Conversely, in the IV interdigital area, symmetry due to bilateral absence of patterns was more frequent among the patients than the controls.

Table VI. Distribution of the simian and Sydney lines by degree of completion in patients with Down's syndrome and in contro subjects ${ }^{1}$

\begin{tabular}{|c|c|c|c|c|c|c|c|c|}
\hline & \multicolumn{4}{|c|}{ Simian } & \multicolumn{4}{|c|}{ Sydney } \\
\hline & \multicolumn{2}{|c|}{ Down's } & \multicolumn{2}{|c|}{ Controls } & \multicolumn{2}{|c|}{ Down's } & \multicolumn{2}{|c|}{ Controls } \\
\hline & M & $\mathbf{F}$ & M & $\mathrm{F}$ & M & $\mathrm{F}$ & M & $\mathrm{F}$ \\
\hline$N$ & 145 & 120 & 203 & 204 & 145 & 120 & 203 & 204 \\
\hline \multicolumn{9}{|l|}{ Complete } \\
\hline Bilateral & 20.0 & 10.0 & 2.0 & 1.5 & 6.2 & 5.8 & 1.5 & 0.5 \\
\hline Unilateral & 22.1 & 21.6 & 4.5 & 3.0 & 9.0 & 20.8 & 5.0 & 7.4 \\
\hline Total & 42.1 & 31.6 & 6.5 & 4.5 & 15.2 & 26.6 & 6.5 & 7.9 \\
\hline \multicolumn{9}{|l|}{ Aberrant } \\
\hline Bilateral & 1.4 & 4.2 & 0 & 0 & 4.8 & 3.3 & 2.0 & 0.5 \\
\hline Unilateral & 7.6 & 8.3 & 3.0 & 1.5 & 13.8 & 13.4 & 9.4 & 11.8 \\
\hline Total & 9.0 & 12.5 & 3.0 & 1.5 & 18.6 & 16.7 & 11.4 & 12.3 \\
\hline Complete plus aberrant & 6.9 & 9.2 & 2.0 & 0 & 4.2 & 8.3 & 2.0 & 1.0 \\
\hline Total, bilateral and unilateral & 57.9 & 53.3 & 11.3 & 5.9 & 37.9 & 51.7 & 19.7 & 21.1 \\
\hline
\end{tabular}

${ }^{1}$ Values are expressed as percentages. 
Table VII. Symmetry and asymmetry in the palmar areas of patients with Down's syndrome and of control subjects ${ }^{1}$

\begin{tabular}{|c|c|c|c|c|c|c|c|c|c|c|}
\hline \multirow[b]{2}{*}{ Palmar area } & \multirow[b]{2}{*}{ Subjects } & \multirow[b]{2}{*}{ Sex } & \multirow[b]{2}{*}{$N$} & \multicolumn{3}{|c|}{ Bilateral symmetry } & \multicolumn{4}{|c|}{ Bilateral asymmetry } \\
\hline & & & & Total & $\begin{array}{l}\text { Bilaterally } \\
\text { absent } \\
\text { pattern }\end{array}$ & $\begin{array}{l}\text { Same } \\
\text { pattern } \\
\text { bilater- } \\
\text { ally }\end{array}$ & Total & $\begin{array}{l}\text { Pattern } \\
\text { in L } \\
\text { hand } \\
\text { only }\end{array}$ & $\begin{array}{l}\text { Pattern } \\
\text { in R } \\
\text { hand } \\
\text { only }\end{array}$ & $\begin{array}{c}\text { Different } \\
\text { pattern } \\
\text { bilater- } \\
\text { ally }\end{array}$ \\
\hline \multirow{4}{*}{ Hypothenar } & Down's & M & 115 & 75.7 & 33.0 & 42.7 & 24.3 & 6.1 & 11.3 & 6.9 \\
\hline & Control & M & 106 & 69.8 & 60.4 & 9.4 & 30.2 & 9.4 & 16.0 & 4.8 \\
\hline & Down's & $F$ & 101 & 65.6 & 31.7 & 33.9 & 34.4 & 6.9 & 12.9 & 14.6 \\
\hline & Control & $\mathbf{F}$ & 110 & 72.7 & 57.3 & 15.4 & 27.3 & 6.4 & 14.5 & 6.4 \\
\hline \multirow[t]{4}{*}{ Thenar/I } & Down's & $M$ & 135 & 97.8 & 97.0 & 0.8 & 2.2 & 2.0 & 0 & 0.2 \\
\hline & Control & $\mathbf{M}$ & 106 & 86.8 & 83.0 & 3.8 & 13.2 & 12.3 & 0 & 0.9 \\
\hline & Down's & $\mathbf{F}$ & 96 & 95.8 & 95.8 & 0 & 4.2 & 1.0 & 2.1 & 1.1 \\
\hline & Control & $F$ & 110 & 89.1 & 88.2 & 0.9 & 10.9 & 5.4 & 1.8 & 3.7 \\
\hline \multirow[t]{4}{*}{ II Interdigital } & Down's & M & 135 & 95.6 & 94.8 & 0.8 & 4.4 & 1.5 & 2.2 & 0.7 \\
\hline & Control & M & 106 & 89.6 & 89.6 & 0 & 10.4 & 1.9 & 7.5 & 1.0 \\
\hline & Down's & $\mathrm{F}$ & 96 & 95.8 & 95.8 & 0 & 4.2 & 3.1 & 1.0 & 0.1 \\
\hline & Control & $F$ & 110 & 90.9 & 90.0 & 0.9 & 9.1 & 0 & 6.4 & 2.7 \\
\hline \multirow[t]{4}{*}{ III Interdigital } & Down's & $\mathrm{M}$ & 133 & 57.1 & 6.8 & 50.3 & 42.9 & 4.5 & 8.3 & 30.1 \\
\hline & Control & M & 106 & 42.4 & 18.9 & 23.5 & 57.6 & 10.4 & 25.5 & 21.7 \\
\hline & Down's & $\mathrm{F}$ & 106 & 66.0 & 8.5 & 57.5 & 34.0 & 3.8 & 10.4 & 19.8 \\
\hline & Control & $\mathbf{F}$ & 108 & 55.6 & 36.1 & 19.5 & 44.4 & 7.4 & 22.2 & 14.8 \\
\hline \multirow[t]{4}{*}{ IV Interdigital } & Down's & M & 134 & 57.5 & 50.7 & 6.8 & 42.5 & 28.4 & 6.7 & 7.4 \\
\hline & Control & $M$ & 107 & 29.9 & 15.0 & 14.9 & 70.1 & 28.0 & 4.7 & 37.4 \\
\hline & Down's & $\mathrm{F}$ & 105 & 56.2 & 52.4 & 3.8 & 43.8 & 27.6 & 8.4 & 7.6 \\
\hline & Control & $F$ & 110 & 50.0 & 17.3 & 32.7 & 50.0 & 14.5 & 3.6 & 31.9 \\
\hline
\end{tabular}

1 Values are expressed as percentages.

\section{Bilateral Asymmetry}

Both patient and control subjects have the highest amount of asymmetry in the III interdigital and IV interdigital areas. In the hypothenar, II interdigital area, and III interdigital area, both patient and control subjects had higher frequencies of patterns in the right hands; in the thenar/I and IV interdigital areas, both groups had more patterns in the left hands. In the hypothenar area, the bilateral assymmetry due to differences in specific pattern types was twice as high in patients as in controls, but the absent patterns did not differ significantly. In the thenar/I and III interdigital areas, patients showed less asymmetry than did controls. In the III interdigital areas, assymmetry in the patients was due mainly to differences in the patterns present in both hands. They also showed a lower frequency of unilateral patterns than did the controls. In contrast, the controls had a 4-5 times higher frequency of different patterns bilaterally in the IV interdigital area than did the patients.

\section{Summary}

The palmar dermatoglyphics of 145 male and 120 female Caucasian patients with Down's syndrome were compared with those of 108 male and 114 female healthy controls. For the simian and Sydney line comparisons, an additional 203 male and 204 female controls were studied. Prints were evaluated for the $\mathrm{C}$ line modal types, $\mathrm{R} / \mathrm{U}$ ratios, and the subclassification of the interdigital palmar patterns described by Plato previously [11]. Hypothenar and thenar/I area patterns were studied according to the classification of Cummins and Midlo [4] Simian and Sydney lines were compared for both complete and aberrant types. The data were evaluated for bilateral symmetry.

The findings in our study suggest that the proposed classifications for $\mathrm{C}$ line modal types and palmar patterns are of value in the study of dermatoglyphic data. The above classifications demonstrate strong bilateral and racial polymorphism, thus presenting further challenges. The $\mathrm{R} / \mathrm{U}$ ratio of Caucasian Down's patients was 10 times higher than that of the Caucasian controls who have a high $\mathrm{R} / \mathrm{U}$ ratio in comparison with other ethnic populations. The values of $R / U$ ratios among Oriental, Negro, and other populations were presented. If similar changes are confirmed for these groups, the $\mathrm{R} / \mathrm{U}$ and $\mathrm{C}$ line types would constitute a reliable criterion for identifying Down's patients. The hypothenar pattern subtypes as described by Cummins and Midlo [4] also showed significant differences. Almost all of the patterns in the hypothenar area of the 
patients were of the ulnar type, whereas the Caucasion controls had mostly radial loops in this area. The diagnostic value of the hypothenar ulnar loop for Down's syndrome among the Oceanic populations may be questioned since in these populations approximately $75 \%$ of hypothenar loops are of the ulnar type.

The III interdigital patterns were not conclusive in characterizing Down's syndrome despite the apparent increase in the frequency of the adjacent types. The IV interdigital patterns suggested differences in the radial type and minor types associated with bilateral asymmetric variations between patients and controls; ulnar frequencies for patients and controls were almost identical. There was a significant difference in simian lines between patients and controls, with the complete type being of greater importance. Although Sydney lines appeared with a higher frequency in patients, their use as a diagnostic criterion for the Down's syndrome does not appear as critical as that of the simian line.

\section{References and Notes}

1. Achs, R., And Harper, R.: Dermatoglyphics. Amer. J. Obstet. Gynecol., 101: 1006 (1968).

2. Alter, M.: Dermatoglyphic analysis as a diagnostic tool. Medicine (Baltimore), 46: 1 (1966).

3. Cummins, H.: Dermatoglyphic stigmata in mongoloid imbeciles. Anat. Rec., 73: 407 (1939).

4. Cummins, H., And Midlo, C.: Finger prints palms and soles. (Blakiston Company, Philadelphia, 1943).

5. Cummins, H., Talley, C., and Platou, V. R.: Palmar dermatoglyphics in mongolism. Pediatrics, 5: $24 \mathrm{I}$ (1950).

6. FANG, T. C.: The third interdigital patterns of the palms of the general British population, mongoloid and non-mongoloid mental defectives. J. Ment. Sci., 96: 780 (1950).
7. Francors, J., Matton-Van Leuven, M., and Debie, S.: Les dermatoglyphes normaux et pathologiques (Leur importance en genetique). J. Genet. Hum., 15: 37 (1966).

8. Penrose, L. S.: The distal triradius $t$ on the hands of parents and sibs of mongol imbeciles. Ann. Hum. Genet., 19: 10 (1954).

9. Penrose, L. S.: Finger-prints, palms and chromosomes. Nature, 197: 933 (1963).

10. Penrose, L. S., and Loesch, D.: Topological classification of palmar dermatoglyphics. J. Ment. Defic. Res., 14: 11 (1970).

11. Pxato, C. C.: Polymorphism of the $\mathrm{C}$ line of palmar dermatoglyphics with a new classification of the $\mathrm{C}$ line terminations. J. Phys. Amer. Anthropol., 33: 413 (1970).

12. Plato, C. C., Brown, P., Gajdusek, D. G.: Dermatoglyphics of the micronesians from the outer islands of Yap. Z. Morphol. Anthropol., 64: 29 (1972).

13. Plato, C. C., and Werteleckr, W.: A method for subclassifying the interdigital patterns: A comparative study of the palmar configurations. Amer. J. Phys. Anthropol., 37: 97 (1972).

14. Rosner, F., Steinberg, F. S., ANd Spriggs, H.: Dermatogiyphic patterns with selected neurological disorders. Amer. J. Med. Sci., 254: 695 (1967).

15. SNEDEKER, D. M.: A study of the palmar dermatoglyphics of mongoloid imbeciles. Hum. Biol., 20: 146 (1948).

16. Turpin, R., ANd Lejeune, J.: Etude dermatoglyphique des paumes des mongoliens et de leurs parents et germains. Sem. Hôp. Paris, 76: 3955 (1953).

17. UCHIDA, I., AND Soltan, H.: Evaluation of dermatoglyphics in medical genetics. Pediat. Clin. North Amer., 10: 409 (1963).

18. WALker, N. F.: The use of dermal configurations in the diagnosis of mongolism. J. Pediat., 50: 19 (1957).

19. WALKER, N. F.: The use of dermal configurations in the diagnosis of mongolism. Pediat. Clin. N. Amer., 531 (1958).

20. Wertelecki, W., Plato, C. C., Fraumeui, J., and Niswander, $\mathrm{J}$. : Dermatoglyphics in leukemia. Lancet, in press.

21. Requests for reprints should be addressed to: Chris C. Plato, Gerontology Research Center, NICHD-NIH, Baltimore City Hospital, Baltimore, Md. 21224 (USA).

22. Accepted for publication November 21, 1972. 